17. Ovsyuchenko, A.N., Trofimenko, S.V., Marakhanov, A.V. et. al. Detailed Geological-Geophysical Studies of Active Fault Zones and the Seismic Hazard in the South Yakutia Region. Russian Journal of Pacific Geology. 2009. Vol. 3(4). P. 356-373. DOI: 10.1134/S1819714009040046.

\title{
Построение систем линеаментов геофизических полей восточного фланга
} Алданского щита

\author{
Тусикова С.А., аспирантка, \\ Институт тектоники и геофизики ДВО РАН, \\ 2. Хабаровск \\ E-mail: svetabon@list.ru
}

Научный руководитель: д.2.-м.н., профессор Трофименко С.В.

Сформулированная американским исследователем Уильямом Хоббсом [18] методика анализа рельефа в виде линейных структур успешно развивалась второй половине XIX века [17] для различных регионов Земли.

Начиная с 60-х гг. XX века, ряд авторов [3] разрабатывали методику дешифрирования рельефа земной поверхности и материалов дистанционного исследования Земли с целью выявления зон скрытых разломов фундамента, тектонических блоков и магматических очаговых структур, контролирующих размещение эндогенного оруденения. В дальнейшем сферу линеаментного анализа были включены и геофизические материалы (карты гравиметрических и магнитометрических съёмок), представленные в виде различных трансформаций аномальных геофизических полей [19].

Линеаментный анализ широко используется при прогнозе месторождений полезных ископаемых, прогнозе землетрясений, выявлении мест развития коллювиальных отложений и оползневых участков, прогнозе путей миграции подземных вод, оценке стабильности блоков геологической среды при проектировании и строительстве сооружений военного, гражданского и промышленного назначения, выборе конкретных вариантов размещения социально и экологически значимых техногенных объектов: линейного транспорта (ЛЭП, газо- и нефтепроводов), плотин, мостов, туннелей, хранилищ вредных отходов, ядерного топлива и др. [1, 17].

В геологической практике выявления и изучения линеаментов используются различные методы: прямые и косвенные, качественные и количественные [8, 10]. Прямые методы выявления и изучения линеаментов связаны с визуальным поиском, выделением и трассированием протяжённых прямолинейных, пересекающих площадь исследования, элементов геофизических полей. Косвенные методы связаны в основном с поиском, выделением и трассированием линеаментов по данным о пространственном размещении различных параметров рельефа [7, 11]. Прямые и косвенные методы поиска, выделения и изучения линеаментов образуют вместе комплекс качественных методов поиска и выявления линеаментов, основы которых заложены в фундаментальных работах $[18,19]$. 
Как и при поиске и выделении линеаментов, так и при их интерпретации применяются качественные и количественные методы, причём в настоящее время качественные методы преобладают.

Качественные методы интерпретации линеаментов и их систем заключаются, как правило, в прямом пространственном сопоставлении составленных схем линеаментов с известными схемами геофизических, геохимических, сейсмических и других полей, схемами и картами различного геологического и географического содержания, а также с разрезами земной коры [4].

Линеаменты по геофизическим полям подразделяются на магнитолинеаменты, гравилинеаменты и сейсмолинеаменты. Линеаментный анализ геофизических полей позволяет выявить и проследить линейные структурные элементы геологического строения, связанные с проявлениями разрывной тектоники, контактами контрастных по свойствам геологических образований, гидротермально-измененными породами, жилами и подобными геологическими телами (пласты, линзы, дайки) [9, 11]. Вышеперечисленные элементы геологического строения проявляются в физических полях как линии, дуги или кольца, соответствующие осям аномалий геофизического поля.

Характерные признаки разломов земной коры, проявляющиеся в гравитационном и магнитном полях, представляют собой линейные индикаторы аномалий геофизических полей (индикаторами разломов), на основании которых строятся количественные модели линеаментов геофизических полей $[7,8,9]$.

Методика и технология геометрических построений линейных индикаторов разломов методами статистического анализа пространственной структуры геофизических полей и рельефа представлены в работах $[7,8,9]$.

Главным критерием эффективности методик линеаментного анализа является достоверность полученных результатов - подтверждаемость геологическими наблюдениями прямой связи линеаментов с разрывными нарушениями в земной коре. Опыт Черновой и др. [16] в области геолого-геоморфологического картирования для решения геолого-поисковых задач на площадях с низкой обнажённостью кристаллических пород показал недостаточность применения одного-двух методов для надёжной и достоверной интерпретации информации и необходимость использования комплекса методов геометризации и дешифрирования линеаментов.

Крупные универсальные ГИС, такие как ArcGIS, MapInfo могут использоваться в рамках существующих технологий линеаментного анализа уже не только как программные средства сбора, упорядочения, хранения, манипулирования и первичной обработки пространственно-привязанных данных, обрабатываемых и получаемых в процессе анализа линейных и кольцевых структур, но и как системы геопространственного и геостатистического анализа результатов обработки исходных данных, позволяющие проводить такие операции над полями линеаментов и кольцевых структур как отбор линеаментов и кольцевых структур по заданным критериям, построение картографических изображений пространственного распределения таких геостатистических показателей линеаментных полей, как плотность и частота, находить точки пересечения линеаментов и многое другое. Однако данные системы по-прежнему остаются системами, предназначенными для удовлетворения лишь основных потребностей в анализе пространственно-скоординированных данных, относящихся к конкретным сферам наук о Земле. 
Другая тенденция заключается в разработке специализированных программ, обеспечивающих работу в рамках одной или нескольких фиксированных технологических схем линеаментного анализа, наиболее известные из них: LESSA, Alina, PhotoLin, COSBALID, LINDENS, LINEAMENT, PLANETAMONITORING [6].

Одним из наиболее устойчивых и часто используемых алгоритмов построения поля штрихов является алгоритм, изложенный в работе Александра Ароновича Златопольского и реализованный в компьютерной программе LESSA (Lineament Extraction and Stripe Statistical Analysis) [1, 2, 10]. Данный алгоритм уже доказал свою эффективность на практике при обнаружении линеаментов на космических изображениях разного пространственного и яркостного разрешения.

Это методика автоматического поиска линейных элементов и анализа их ориентации, расположения. Программы, реализующие LESSA, выявляют линейные элементы рисунка и описывают их свойства так, как это принято в геологических исследованиях: розы - диаграммы, плотности линейных элементов, протяжённые линеаменты. Предоставляется и много новых видов описания: характеристики формы

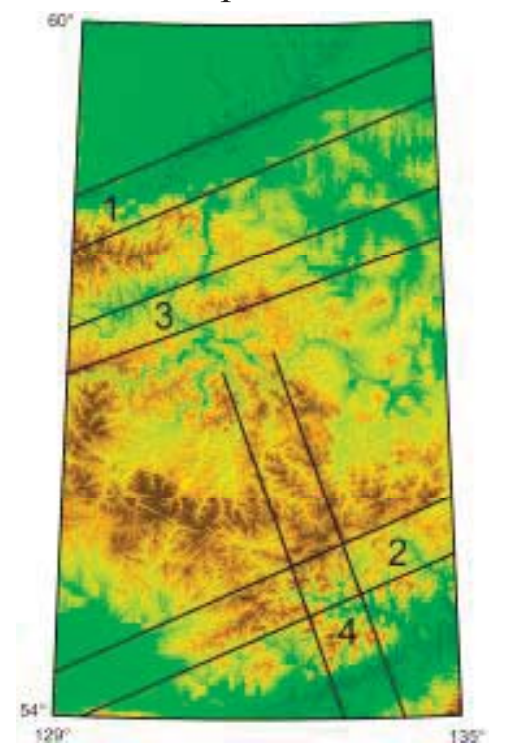
роз-диаграмм, вектора и линии вытянутости, сходство соседних роз-диаграмм и др. [5].

Первые результаты построения линеаментных структур показали высокую эффективность данных модели для территорий Алданского щита и Приамурья при изучении сейсмичности $[15,16,14,13,20]$.

В данном обзоре изложена технология построения линеаментов, на основе которой построена схема линейных элементов геофизических полей восточной области Алдано-Станового блока в азимутах (70-340 ${ }^{\circ}$ (рис. 1).

Рис. 1. Система линеаментов в азимутах (70-340) ${ }^{\circ}$ на цифровой модели рельефа. Обозначения: $1-3-$ ограничение блока в азимуте $70^{\circ} ; 4-$ простирание центрального блока в азимуте $340^{\circ}$

Список литературы:

1. Бондур В.Г., Зверев А.Т., Гапонова Е.В. Линеаментный анализ космических изображений сейсмоопасных территорий России // Современные проблемы дистанционного зондирования Земли из космоса. 2012. Т. 9. № 4. С. 213-222.

2. Златопольский А.А. Методика измерения ориентационных характеристик данных дистанционного зондирования (технология LESSA) // Современные проблемы дистанционного зондирования Земли из космоса. 2008. Вып. 5. Т. 1. С. 102-112.

3. Изосов Л.А., Ли Н.С. Линеаментный анализ при тектонических и металлогенических построениях в Япономорском регионе // Региональные проблемы. 2014. T. 17. № 1. С. 9-14.

4. Кац Я.Г., Полетаев А.И., Румянцева Э.Ф. Основы линеаментной тектоники. М.: Недра, 1986. 140 с.

5. Линеаментный анализ: описание. [Электронный ресурс]. - Режим доступа: http://www.lineament.ru/index.htm. - (дата обращения: 19.01.2017) 
6. Малинников В. А., Учаев Д. В., Учаев Дм. В., Фам Соан Хоан. Разработка алгоритмов и программ линеаментного анализа цифровых изображений земной поверхности // Известия высших учебных заведений. Геодезия и аэрофотосъемка. 2011. № 1. С. 67-73.

7. Статива А.С., Трофименко С.В. Методика и технология выделения систем разломов Алданского щита // Горный информационно-аналитический бюллетень (научно-технический журнал). 2006. Т. 17. № 3. С. 155-167.

8. Статива А.С., Трофименко С.В. Построение систем разломов Алданского щита по геофизическим данным // Горный информационно-аналитический бюллетень (научно-технический журнал). 2006. Т. 17. № 3. С. 193-198.

9. Трофименко С.В. Тектоническая интерпретация статистической модели распределений азимутов аномалий гравимагнитных полей Алданского щита // Тихоокеанская геология. 2010. Т. 29. № 3. С. 64-77.

10. Трофименко С.В., Гильманова Г.З., Никитин В.М., Колодезников И.И. Линеаментный анализ пространственного поля сейсмичности северного сегмента Амурской микроплиты // Наука и образование. 2016. № 1 (81). С. 7-13.

11. Трофименко С.В., Гриб Н.Н., Никитин В.М., Статива А.С. Интерпретация статистической модели аномалий гравимагнитных полей Алданского щита // Наука и образование. 2011. № 1 (61). С. 40-45.

12. Тусикова С.А., Колягина О.А. Линейные индикаторы речной сети восточного фланга Алдано-Станового блока. Обзор работ и первые результаты // Инновационная парадигма устойчивого развития науки. Теория и практика. /Сборник научных статей международной научно-практической конференции Санкт-Петербургского Центра Системного Анализа 15-16 декабря 2016г. СПб.: Изд-во: КультИнформПресс. 2016. C.20-23. http://elibrary.ru/item.asp?id=27478567.

13. Тусикова С.А., Колягина О.А. Линейные элементы геофизических полей восточной части Алдано-Станового блока. Обзор работ и первые результаты //Инновационная парадигма устойчивого развития науки. Теория и практика. /Сборник научных статей международной научно-практической конференции СанктПетербургского Центра Системного Анализа 15-16 декабря 2016г. СПб.: Издво: КультИнформПресс. 2016. С.23-26. http://elibrary.ru/item.asp?id=27478567.

14. Тусикова С.А. Системы геофизических и топографических линеаментов Алданского щита и северо-восточного сегмента Амурской микроплиты //Ъволюция научного знания: сборник статей международной научной конференции /Россия, Москва, 28-29 ноября 2016 г. [Электронный ресурс] / под ред. проф. А.А. Алпатова, Р.В.Овчаровой. М.: РусАльянс Сова, 2016. С. 106-114.

15. Тусикова С.А. Методы и технологии линеаментного анализа геофизических полей. На примере Алдано-Станового блока. // Эволюция научного знания: сборник статей международной научной конференции / Россия, Москва, 28-29 ноября 2016 г. [Электронный ресурс] / под ред. проф. А.А. Алпатова, Р.В. Овчаровой. М.: РусАльянс Сова, 2016. С. 98-105.

16. Чернова И.Ю., Нугманов И.И., Кадыров Р.И. Автоматизированный линеаментный анализ. Учебное пособие. 2013.

17. Шереметьева Е.В., Богословский В.А., Кочев Д.З., Полетаев А.И., Спиридонов А.В. Линеаментный анализ как наиболее экологический и инвестиционно привлекательный способ оценки инженерно-геологических условий территорий проектируемого строительства // В сборнике: Сергеевские чтения. Устойчивое 
развитие: задачи геоэкологии (инженерно-геологические, гидрогеологические и геокриологические аспекты) Молодежная конференция. Материалы годичной сессии Научного совета РАН по проблемам геоэкологии, инженерной геологии и гидрогеологии. Научный совет РАН по проблемам геоэкологии, инженерной геологии и гидрогеологии. 2013. С. 204-208.

18. Hobbs W. N. Lineaments of the Atlantic border region // Bull. Geol. Soc Amer. 1904. Vol. 15. P. 483-506.

19. Hubbert, M. K. Theory of scale models as applied to the study of geologic structures // Geological Society of America Bulletin. 1937. Vol. 48. P. 1459-1520.

20. Trofimenko S.V., Grib N.N., Melnikov A.A., Merkulova T.V. Systems of Lineaments of Magnetic and Gravity Anomalies in the Zone of Convergent Interaction of the Amur and the Eurasian Tectonic Plates // Modern Applied Science. Vol. 9. No. 8. 2015. P. 195-203. doi:10.5539/mas.v9n8p195. URL: http://dx.doi.org/10.5539/mas.v9n3p195.

\section{Исследование применения скважинной гидродобычи на угольных месторождениях Южной Якутии}

Халзанов А.Н., заведующий отделением, ГАПОУ РС (Я) «Южно-Якутский технологический колледж», 2. Нерюнгри E-mail: halzanov@inbox.ru

Научный руководитель: к.т.н., доцент Рочев В.Ф.

Скважинная гидродобыча (СГД) представляет собой способ дистанционной подземной разработки месторождений через скважины, при котором полезные ископаемые переводятся в состояние суспензии, способной к транспортировке на поверхность. Его можно использовать при отработке запасов, сложенных легкодиспергируемыми рыхлыми или слабосвязанными полезными ископаемыми.

Добыча угля с использованием комплексной технологии СГД создает большие преимущества перед традиционными способами добычи, позволяет по-новому оценить эксплуатируемые, отработанные и вновь открытые месторождения. Установлено, что данная технология обеспечивает технологический, экономический и экологический эффект.

К преимуществам данного комплексного способа отработки угольных месторождений можно отнести:

- небольшие объемы горно-капитальных работ и сроки отработки эксплуатационных модулей;

- возможность эффективно отрабатывать нарушенные месторождения;

- ведение всех добычных работ с поверхности, резкое сокращение затрат труда, повышение безопасности труда горнорабочих;

- сравнительно малые капиталовложения и сроки строительства горнодобывающих объектов,

- небольшие издержки производства, обеспечивающие невысокую себестоимость продукции; 